\title{
Learning outcome, presence and satisfaction from a science activity in Second Life
}

Ioannis Vrellis

Department of Primary Education, University of Ioannina, Greece

\author{
Nikolaos Avouris \\ Department of Electrical and Computer Engineering, University of Patras, Greece
}

\author{
Tassos A. Mikropoulos \\ Department of Primary Education, University of Ioannina, Greece
}

\begin{abstract}
Although problem-based learning (PBL) has many advantages, it often fails to connect to the real world outside the classroom. The integration with the laboratory setting and the use of information and communication technologies (ICTs) have been proposed to address this deficiency. Multi-user virtual environments (MUVEs) like Second Life (SL) are 3D collaborative virtual environments that could act as complementary or alternative worlds for the implementation of laboratory PBL activities offering low-cost, safe, and always available environments. The aim of this study was to compare a simple laboratory PBL activity implemented in both the real and virtual worlds, in terms of learning outcome, satisfaction, and presence. The sample consisted of 150 undergraduate university students. The results show that the MUVE provided similar learning outcome and satisfaction to the real-world condition. Presence was positively correlated to satisfaction but not to the learning outcome. Finally, there are indications that the MUVE was perceived as more pleasurable and informal learning environment, while reality was perceived as more stressful.
\end{abstract}

\section{Introduction}

\section{Problem-based learning}

Although problem solving is regarded as the most important learning outcome for life, students are rarely required to solve meaningful problems as part of their curricula (Jonassen, 2000). Problem-based learning (PBL) is "an instructional method that initiates students' learning by creating a need to solve an authentic problem. During the problem solving process, students construct content knowledge and develop problem-solving skills as well as self-directed learning skills while working toward a solution to the problem” (Hung, Jonassen, \& Liu, 2008, p. 486). PBL is based on social constructivism and situated learning (Hmelo-Silver \& Eberbach, 2012). In PBL, learners actively construct knowledge in small collaborative groups by being reflective and self-directed. The teacher acts as a facilitator (or metacognitive coach) guiding student learning, rather than being the provider of knowledge (Gallagher, Sher, Stepien, \& Workman, 1995; Hmelo-Silver, 2004).

PBL instruction varies according to student self-directness and problem-structuredness (Barrows, 1986; Jonassen, 2000). Well-structured problems focus on correct, efficient solutions and are typically found at the end of textbook chapters, while ill-structured problems are encountered more often in everyday and professional practice and focus more on decision articulation and argumentation. In pure PBL, learning is initiated with the presentation of an ill-structured problem to a group of five to eight students, who will work with minimal guidance (high self-directness) for at least 1 week both collaboratively and individually (Allen \& Tanner, 2003; Hung et al., 2008; Kelly \& Finlayson, 2007).

\section{Connecting PBL to the real world}

“Although PBL problems strive to connect to the real world outside the classroom, they can sometimes fail to get beyond being paper-and-pencil activities that connect only with a student's "mind's eye" of experience in the real world" (Allen \& Hodson, 2003, p. 201). Two ways to address this deficiency, especially in science and engineering, are (a) connecting PBL problems to the laboratory setting (Allen \& Hodson, 2003; Feisel \& Rosa, 2005) and (b) using information and communication technologies (ICTs) 
like multimedia, virtual reality, and the Internet in order to create a more situated and authentic context (Hung et al., 2008).

\section{Connecting PBL to the laboratory}

PBL integration in the laboratory setting can be hindered by several factors. Laboratory classes typically include teacher-structured recipe-type exercises or experiments (Domin, 1999), where students are expected to follow exactly carefully prescribed procedures over a set time (Kelly \& Finlayson, 2007; McDonnell, O'Connor, \& Seery, 2007). These types of exercises are designed in order to minimise resources, particularly time, space, equipment, and personnel at the cost of deep understanding and critical thinking (Domin, 1999; Kelly \& Finlayson, 2007). Researchers have proposed an adapted form of pure PBL that can be more easily implemented in a laboratory setting, with the following characteristics (Allen \& Hodson, 2003; Bowe, Flynn, Howard, \& Daly, 2003; Domin, 1999; Gallagher et al., 1995; Kelly \& Finlayson, 2007; Kohnle, Brown, Rae, \& Sinclair, 2012; McDonnell et al., 2007):

- $\quad$ session duration similar to that of traditional lab sessions

- $\quad$ use of relatively structured problems, that cover only one pre-defined area of knowledge (problems less ill-structured that in pure PBL)

- $\quad$ smaller student groups (usually pairs) in order to allow for easy access to lab equipment and tools

- incorporation of a pre-lab session where initial discussion of the problem, revision of theory, technical skills and etiquette take place. This session lowers the self-directness of the participants relative to pure PBL, but is important because students usually have varied content and self-directed learning backgrounds.

Using ICTs for PBL

The advancement of ICTs has enabled new ways to experience laboratory education that could lessen the restrictions of traditional hands-on laboratories (Fayolle, Gravier, \& Jailly, 2010; Feisel \& Rosa, 2005). For example, virtual laboratories are digital environments that simulate existing or non-existing laboratories with the following advantages:

- It is usually possible to simulate experiments independently of the scale of space and time of the various physical phenomena and to perceive phenomena not directly observable by human senses (de Freitas \& Veletsianos, 2010; Feisel \& Rosa, 2005; Svajger \& Valencic, 2003).

- The spatial and temporal capacity of the virtual laboratories is practically unlimited, since it is based on widely available ICT infrastructures.

- $\quad$ There is no need for expensive equipment and expendable supplies.

- $\quad$ Experimentation is safe (Cobb, Heaney, \& Henderson-Begg, 2009; Feisel \& Rosa, 2005; Svajger \& Valencic, 2003).

- The participants can control the learning pace and repeat experiments for better understanding (Cobb et al., 2009; de Freitas \& Veletsianos, 2010; Lee, Wong, \& Fung, 2010).

- Because there is no possibility of equipment damage (Torres et al., 2006) and injury and time constraints (Kelly \& Finlayson, 2007), learners do not need to follow strict procedures (behavioural model) and can freely experiment and try out different approaches in order to actively construct their knowledge (constructivist model) (Cobb et al., 2009; de Freitas \& Veletsianos, 2010; Lee et al., 2010).

- Virtual laboratories can be designed to resemble actual physical environments, in order to offer more realistic and situated learning.

- Virtual laboratories can accommodate distance learners (Feisel \& Rosa, 2005).

- It is possible to exclude all didactically non-relevant objects and processes from the experiment (Svajger \& Valencic, 2003).

- It is possible to regulate the complexity of the environment to suit different educational levels (Chen, 2006; Svajger \& Valencic, 2003).

- It is possible to implicitly evaluate student performance (Svajger \& Valencic, 2003).

- It is possible to enhance the environment with visualizations and other learning materials. 


\section{Multi-user virtual environments: technical characteristics and learning affordances}

Multi-user virtual environments (MUVEs or virtual worlds) are a relatively new medium used both in traditional classrooms and in distance education (Dickey, 2005; Hew \& Cheung, 2010; Salmon \& Hawkridge, 2009), offering promising instructional benefits (Chen, 2006). They are 3D digital spaces that can be simultaneously accessed by multiple participants represented through avatars, who are able to communicate with each other and to enact collaborative activities (Dede, Nelson, Ketelhut, Clarke, \& Bowman, 2004). The recent emergence of MUVEs as a teaching and learning tool is "stemming largely from a set of socio-technical transitions such as wider access to broadband, the development of powerful technologies and platforms, the emphasis upon social and experiential interactions, and advances in the uses and applications of the internet" (de Freitas \& Veletsianos, 2010, p. 3). They have received considerable attention as enhanced computer supported collaborative learning (CSCL) environments, with the expectation that they will provide an engaging and near face-to-face quality of interaction over distance (Sutcliffe \& Alrayes, 2012). The most frequently used MUVEs for educational research are Active Worlds and Second Life (SL) (Bulu, 2012). Although Active Worlds has been used by many researchers in the field (Barab, Sadler, Heiselt, Hickey, \& Zuiker, 2006; Dede et al., 2004), SL has a far larger and active community, and many educational institutions are using it for teaching and learning, both locally and from a distance (Callaghan, McCusker, Losada, Harkin, \& Wilson, 2009; de Freitas \& Veletsianos, 2010; Salmon, 2009).

MUVEs provide users with a common 3D space with adequate representational fidelity and various types of interactivity, where they can act on the objects in the environment, observe the outcomes of their actions, and learn by doing (Hew \& Cheung, 2010). This leads to a sense of spatial presence, which measures whether someone feels like "being there," in the virtual environment (Heeter, 1992). Also, through the use of avatars, MUVEs provide identity construction and embodied verbal and non-verbal synchronous communication (Hew \& Cheung, 2010). This leads to a sense of social presence (Dalgarno \& Lee, 2010; Dickey, 2005a), which measures whether someone feels like "being with another" (Biocca, Harms, \& Burgoon, 2003, p. 456). The sense of spatial and social presence, that is, the subjective psychological response of the learner to the technological characteristics of the virtual environment, transforms them into learning affordances: enhanced spatial knowledge representation, safe experiential learning, increased motivation and engagement, improved transfer of knowledge though contextualisation, effective collaboration (Dalgarno \& Lee, 2010). These learning affordances underpin the constructivist and situated approach to learning, on which the instructional strategy of PBL is grounded (Hmelo-Silver \& Eberbach, 2012; Lee et al., 2010). The sense of presence supports engagement and collaboration and has been identified as having key benefits for education and training purposes (de Freitas \& Veletsianos, 2010), especially when using situated and collaborative learning methods like PBL (Hung et al., 2008). More specifically, presence in a virtual environment may positively influence the learning outcome and learners’ satisfaction (Bulu, 2012; Lee et al., 2010).

\section{Aim of the study}

The aim of this study was to empirically investigate whether MUVEs can effectively act as platforms for laboratory PBL activities in terms of learning outcome and student satisfaction in higher education. The approach was experimental, comparing two implementations of a simple laboratory PBL activity involving three participants (two students and the facilitator): (1) in the real world (control condition) and (2) in a MUVE (experimental condition). A secondary aim was to investigate whether the learning outcome and satisfaction are correlated to presence in the virtual world condition.

\section{Literature review}

The aim of the literature review was to find studies that involved educational uses of MUVEs in higher education, with laboratory PBL content and experimental method. No studies were found that satisfied all these criteria. The most relevant studies are presented below in the following order: first, those that were done in primary and secondary education and then those that were done in higher education. In each case the studies with experimental approach were examined first.

A study that involved inquiry learning and had experimental approach was done by Hickey, IngramGoble, and Jameson (2009) in primary education. They created Quest Atlantis in Active Worlds where learners navigate through the 3D space, interacting with other player and non-player characters (NPC) in 
order to complete various tasks. One of the quests was the Taiga Park, where learners had to investigate the ecological problem of the fish population declining in a river, by interviewing the NPCs, and collecting and analysing water samples. A group of 116 sixth-grade students was used in order to compare the Taiga Park MUVE $(N=54)$ with the more conventional textbook approach $(N=62)$. The learning outcomes were assessed at three levels: close (activity-oriented), proximal (curriculum-oriented), and distal (science standard-oriented), but no statistically significant differences were found between the two environments. In a similar study in secondary education Ketelhut, Nelson, Clarke, and Dede (2010) created the virtual town River City in Active Worlds, in order to assess various types of inquiry learning in biology. Using a sample of 2000 middle-school students, the researchers compared three MUVE-based learning strategy variants (guided social constructivist, expert modelling and coaching, legitimate peripheral participation), with a paper-based real life equivalent. They found no differences between the four groups using a post-test, although they argued that other types of performance assessment such as reports are needed to evaluate students' understanding of the topic. They concluded that MUVEs can be used to teach biology as well as or better than traditional approaches. In another study in secondary education Lee et al. (2010) followed a structural equation modelling approach in order to find factors that influence learning outcomes in desktop VR learning environments. They used V-Frog, a single user VRbased dissection simulator, with 232 secondary school students and found that the learning outcome and satisfaction are positively correlated to presence. Nevertheless, presence was not measured with a standardised literature-based questionnaire, but with a single item developed by the researchers.

In a study in higher education Dalgarno, Bishop, Adlong, and Bedgood (2009) evaluated the effectiveness of a web-based virtual chemistry laboratory in familiarising distance education undergraduate university students with laboratory space, equipment, and procedures. An experimental design was used, with a group of 22 students taking a tour in the virtual laboratory $(N=11)$ and actual laboratory $(N=11)$. There were no significant differences on the measured familiarity with laboratory layout and equipment between the groups, indicating that a virtual laboratory is an effective preparative tool especially for distance students. In another study that also involved laboratory education, Cobb et al. (2009) used 85 undergraduate and postgraduate university students in order to determine whether the learning gains produced by conducting a biotechnology experiment (polymerase chain reaction) in a virtual laboratory in SL $(N=50)$ were similar to those gained by viewing a demonstration of the same experiment in the physical world laboratory $(N=35)$. The results show learning gain in both environments, although no significant difference between them was detected. Student satisfaction was found to be high but was measured only in the virtual lab condition.

In another study in higher education Beltrán Sierra, Gutiérrez, and Garzón-Castro (2012) compared an undergraduate university course in electronics, using a group of 180 students. The first group $(N=90)$ followed the subject with the traditional on-site lessons, while the second group $(N=90)$ followed a mixed approach that combined traditional on-site lessons with lessons in a virtual classroom in SL. They concluded that although there were no significant differences in the learning outcomes between the two groups, the SL condition was more pleasurable, increased motivation to learn, and promoted participation and investigation. In another study that involved PBL, Sutcliffe and Alrayes (2012) compared a survival prioritisation problem. Undergraduate and postgraduate students $(N=63)$ organised in groups of 3 had to find the best ranking in a list of items which might be useful or useless for survival, in SL, in Blackboard (a 2D collaborative learning environment) and in a face-to-face control condition. Using a repeated measures design, they found no performance differences between the three conditions. Although many participants commented that SL was enjoyable and fun, quantitative measures showed that they were more satisfied with the face-to-face condition, which was also quicker and easier to use. Bulu (2012) investigated presence and satisfaction in SL using 46 undergraduate university students. These students used a virtual campus in SL for collaboration, meetings, and socialising during a course for a semester. She used literature-based questionnaires in order to measure spatial presence (Slater, McCarthy, \& Maringelli, 1998; Slater, Sadagic, Usoh, \& Schroeder, 2000; Slater, Usoh, \& Steed, 1994) and social presence (Kreijns, Kirschner, Jochems, \& van Buuren, 2007) and found that spatial and social presence are predictors of students' satisfaction. Finally, Vrellis, Papachristos, Bellou, Avouris, and Mikropoulos (2010) designed a laboratory PBL activity regarding the law of reflection in SL. They evaluated it with 30 undergraduate university students in terms of design issues, learning outcome, presence, and satisfaction. They found that the activity was well designed and produced measurable learning outcome. The participants felt high social presence and moderate spatial presence, and were satisfied by the virtual experience. 
The above literature review indicates a lack of research on the subject of this paper. Some of the reviewed studies used participants from primary or secondary education (Hickey et al., 2009; Ketelhut et al., 2010; Lee et al., 2010). Others involved non-PBL activities (Beltrán Sierra et al., 2012; Bulu, 2012; Cobb et al., 2009; Dalgarno et al., 2009; Lee et al., 2010) or collaborative inquiry-based PBL activities (Hickey et al., 2009; Ketelhut et al., 2010; Sutcliffe \& Alrayes, 2012). Also some studies did not use an experimental method (Bulu, 2012; Lee et al., 2010; Vrellis et al., 2010). The novelty of our study resides in the fact that it focuses on the experimental evaluation of a hands-on virtual laboratory PBL activity in higher education.

Based on evidence from the literature review, hypotheses regarding the learning outcome, satisfaction, and presence were formulated. Studies suggest that MUVEs generally have equivalent learning outcome with real life settings (Beltrán Sierra et al., 2012; Cobb et al., 2009; Dalgarno et al., 2009; Hickey et al., 2009; Ketelhut et al., 2010; Sutcliffe \& Alrayes, 2012) and indicate that presence may be positively correlated to the learning outcome (Lee et al., 2010). Therefore, the following two hypotheses $(\mathrm{H})$ were formulated:

- Hypothesis 1. Student learning outcomes will not differ between conditions; and

- Hypothesis 2. Student learning outcomes will be positively correlated to presence in the virtual world condition.

Literature results about satisfaction are more ambivalent, rating either the real world (Sutcliffe \& Alrayes, 2012) or the virtual world (Beltrán Sierra et al., 2012) as more satisfactory. Our experience (Vrellis et al., 2010) suggests that MUVEs provide high satisfaction to the participants, and we believe that they could be at least as satisfactory as reality. Indications also exist that satisfaction may be positively correlated to presence (Bulu, 2012; Lee et al., 2010; Salzman, Dede, Loftin, \& Chen, 1999). Therefore, the following two hypotheses were formulated:

- Hypothesis 3. Student satisfaction will not differ between conditions; and

- Hypothesis 4. Student satisfaction will be positively correlated with presence in the virtual world condition.

\section{Method}

The approach was experimental, comparing learning outcome and satisfaction between the real world (control condition) and virtual world (experimental condition). The University of Ioannina did not require an ethics approval for this study.

\section{Participants}

The participants were recruited from the Department of Primary Education, the University of Ioannina, Greece. An announcement regarding the study was sent to all third-year students of the department. Student participation was voluntary, motivated by a small bonus (5\%) in the marks of two of their courses. Participants registered in pairs. Eventually, 150 undergraduate students registered for the study: 131 women and 19 men. The imbalanced gender ratio of the participants is typical in education departments in Greece. Nevertheless, it was accepted because a balanced sample would be either too small or unattainable. Students were assigned to one of two groups: the real world Group R (control group) and the virtual world Group V (experimental group). Group V consisted of 78 students (67 women, 11 men; age: mean $=20.86, S D=1.21$ ) who had attended the semester course "Educational uses of MUVEs" and thus had experience in using SL. Group R consisted of 72 students (64 women, 8 men; Age: mean $=20.96, S D=1.68$ ) who had not attended any SL course and reported no experience in SL.

The assignment of participants to the two groups was not randomised because we wanted Group V to be comprised of experienced SL users for two reasons: (a) so that they would be able to operate the SL environment effortlessly and (b) in order to minimise the novelty effect. Consequently, this study is considered quasi-experimental. The fact that Group V participants came mainly from a science or technology background is discussed below as a possible confounding variable of this design. 


\section{The MUVE: SL}

According to a review study by Wang and Burton (2012), SL is considered to be the most mature and popular virtual world being used in education. Along with many other research teams, our team owns land in SL (the Earthlab Education Island) for the implementation and evaluation of various learning activities ranging from classroom lessons (Papachristos, Vrellis, Natsis, \& Mikropoulos, 2014) to laboratory PBL activities (Vrellis et al., 2010; Vrellis, Papachristos, Natsis, \& Mikropoulos, 2012). Our experience indicates that SL provides adequate technical affordances for the creation of learning activities and also engenders positive attitudes in the users. Consequently, SL was the platform of choice for the current study.

\section{The laboratory PBL activity}

The reflection of light was chosen as the topic of the activity, involving the laws of reflection and the relevant trigonometry. This is because it is not too easy - although relatively simple and familiar to the students of primary education; it can be implemented easily and cost-effectively both in the real and the virtual worlds; and it takes advantage of the spatial representational capability of MUVEs.

The activity involved three main objects: a laser source, a rotating mirror, and a target (Figure 1). Participants had to collaborate in order to find the correct angle $\mathrm{x}$ of the mirror that would reflect the incident laser beam onto the target. The problem had to be solved in one attempt, after performing distance measurements and trigonometric calculations. A trial and error approach, such as trying different angles on the mirror was not allowed. Activity objects in the real world were constructed using everyday materials (Figure 2). An exact replica of the room and objects was created in SL (Figure 3).

The following tools were available to participants:

- two rulers for measuring horizontal and vertical distances (The real rulers were made of wooden rods that had measuring tape glued to them.)

- a poster illustrating the law of reflection

- three posters illustrating the definitions and values of the basic trigonometric functions (sine, cosine and tangent)

- a whiteboard (In SL this was based on the free web-based collaboration tool Scribblar, http://www.scribblar.com.)

- a calculator.

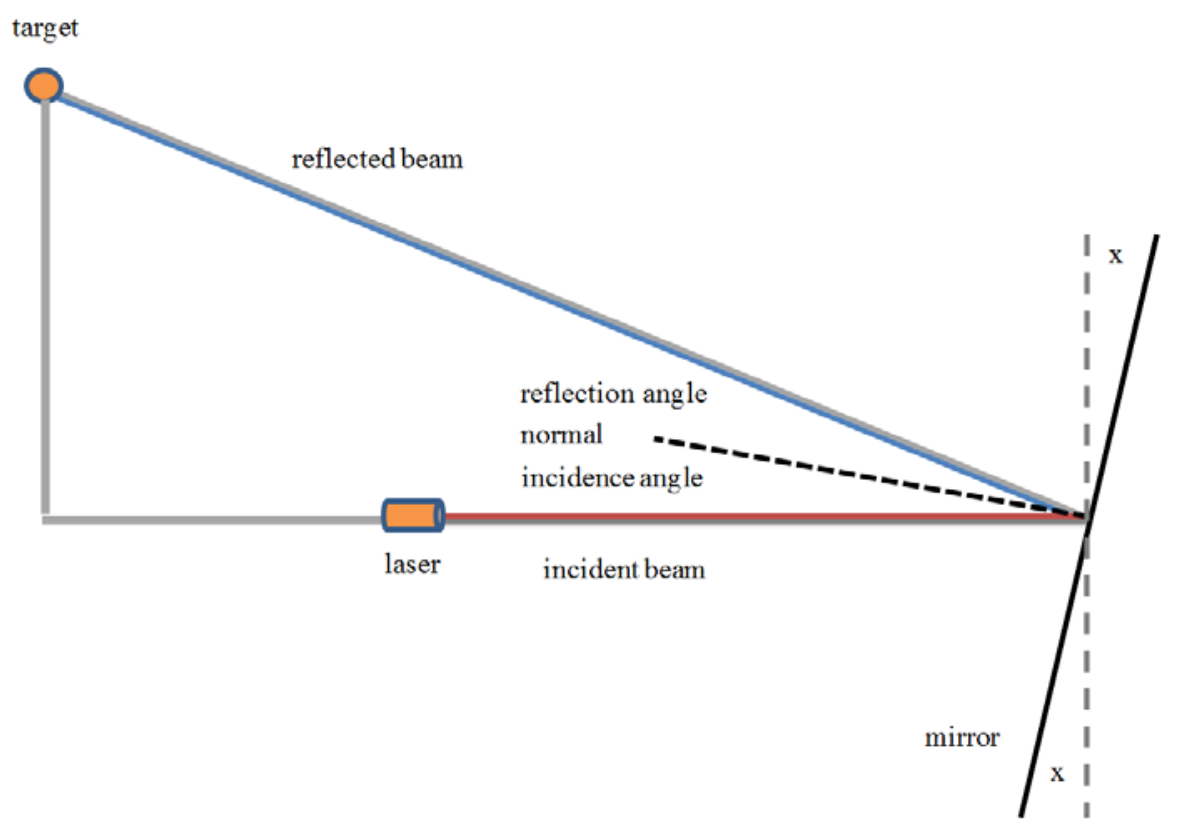

Figure 1. Model of the laboratory PBL activity 


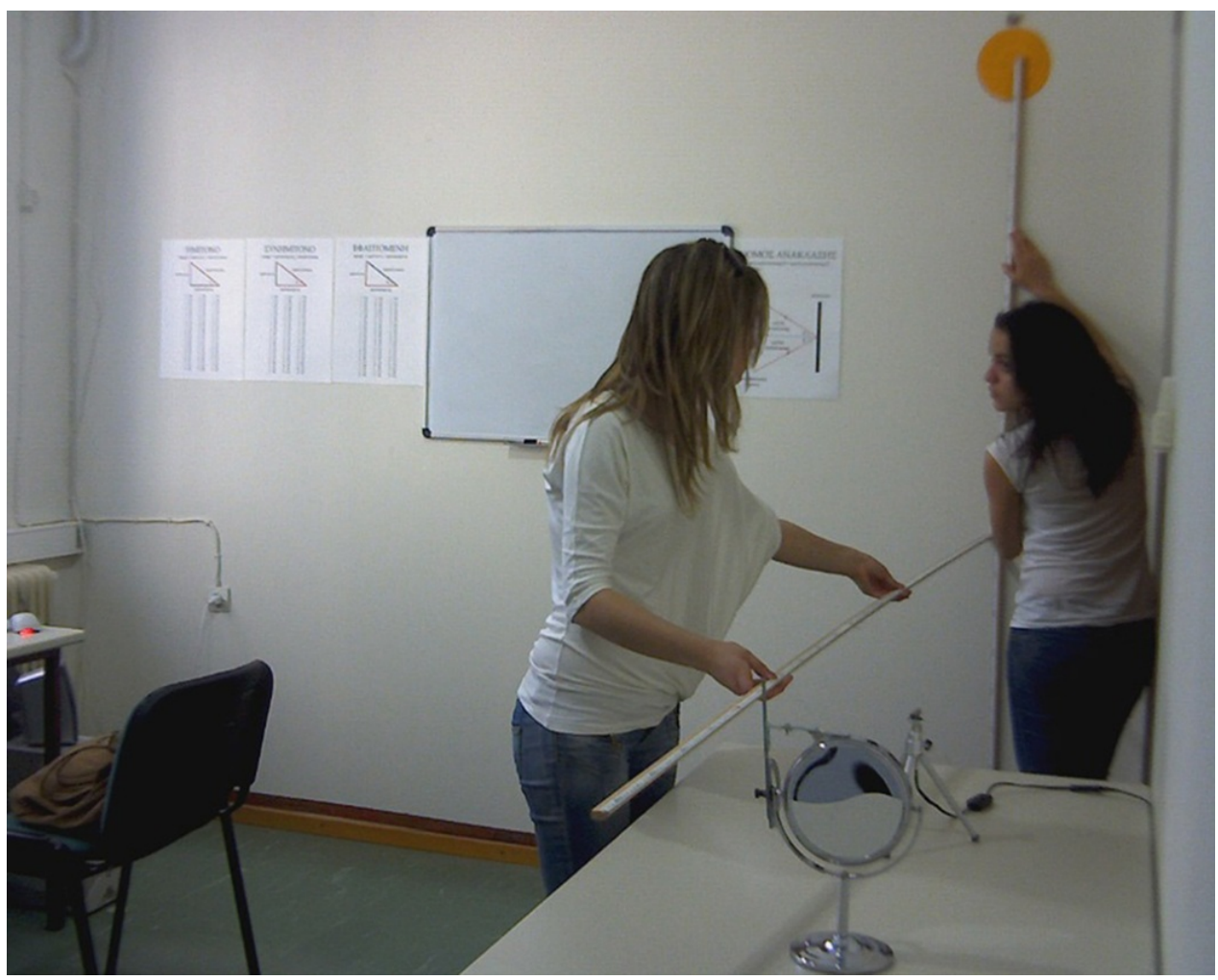

Figure 2. Real world setting
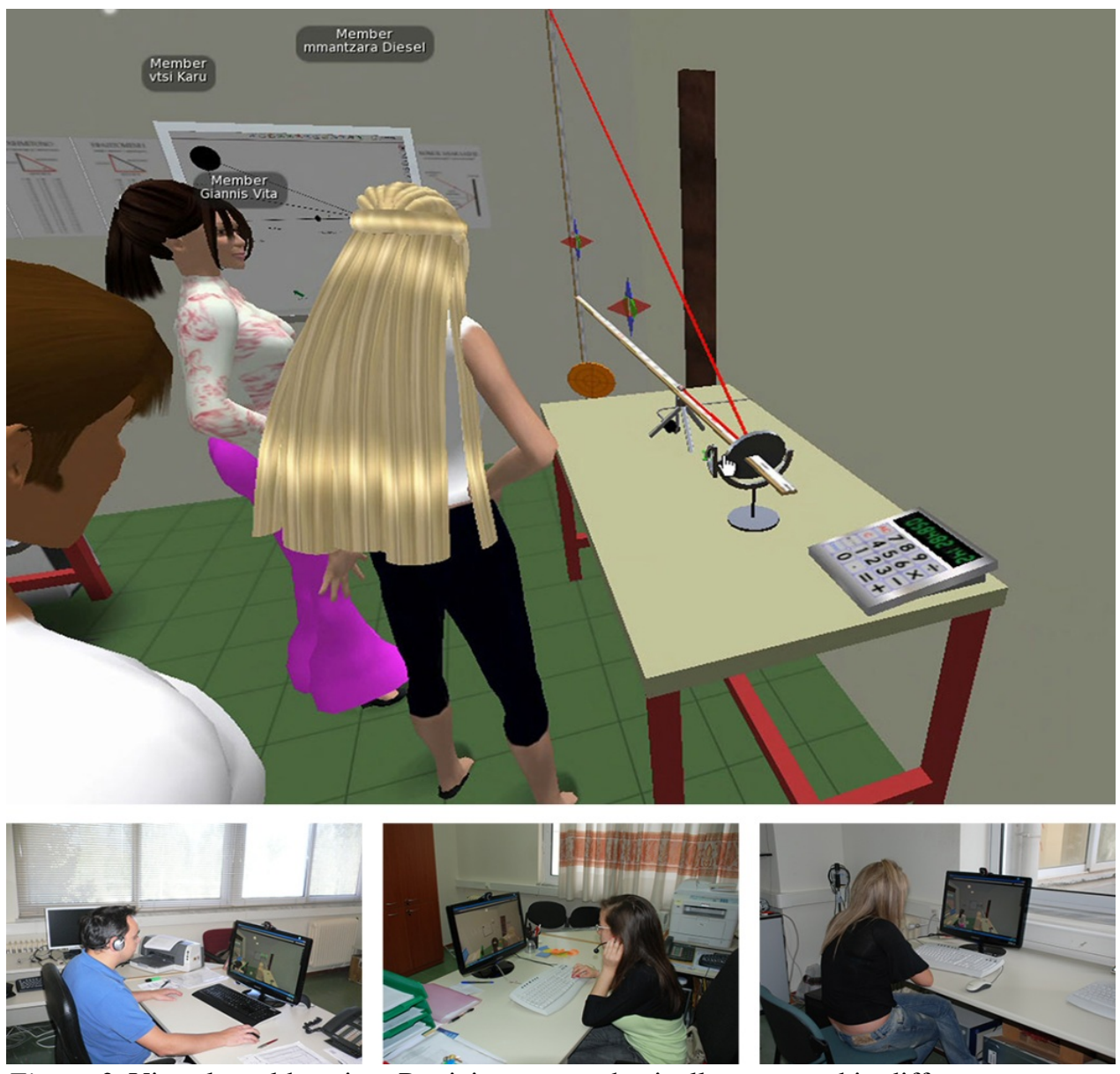

Figure 3. Virtual world setting. Participants are physically separated in different rooms. 
The activity was designed according to the adapted form of pure PBL for the laboratory setting, as described in the Introduction. It had relatively low self-directedness (a short pre-lab introductory session was included) and the problem was well structured. According to the taxonomy proposed by Barrows (1986) this problem is a lecture-based problem-solving activity, while according to the taxonomy of Jonassen (2000) it is a story problem. Nevertheless, it is still a problem-based activity based on constructivism, which is realistic, complex enough, reflective and collaborative (Jonassen, 1994).

An initial evaluation of the activity in SL had been conducted in a previous pilot study with 30 undergraduate university students (Vrellis et al., 2010). Initial findings indicate that the activity was well designed, had a reasonable degree of difficulty, engaged the students, and resulted in positive learning outcomes. The realism of the environment was adequate, and the students showed a preference for inworld object manipulation, educational material and tools. The sense of social dimensions of presence was high, while the sense of spatial presence was moderate. All participants were very satisfied with their collaboration in the virtual environment and the overall experience. Moreover, they enjoyed the activity and considered that the participation in learning activities in MUVEs was very important for their education.

\section{Instruments}

The empirical data regarding demographics, learning outcomes, presence, and satisfaction was collected using tests and questionnaires.

The demographics questionnaire included items regarding age, gender, secondary school background (humanities, science, technology) and number of university courses attended on mathematics and physics. Learning outcomes were measured using a pre post test (Table 1), a post comprehension test (Table 2) and a post drawing test representing the activity model (similar to Figure 1). Pre-post test measured basic declarative knowledge, for example, definitions of trigonometry and the law of reflection. The comprehension and drawing test measured understanding of the particular activity. An overall learning outcome score (on a scale of 0-16) was calculated as the sum of the post-test (scale 0-4), the comprehension test (scale 0-4) and the drawing test (scale 0-8).

Table 1

Pre-post test

1. In a right-angled triangle, trigonometric functions relate:

$\square \quad$ The three sides

$\square \quad$ The three angles

$\square \quad$ Two of the sides with one of the angles

2. If you know two sides of a right-angled triangle and you want to find one of the angles, which mathematical tool would you use?

\begin{tabular}{ll}
\hline$\square$ & The Pythagorean theorem \\
$\square$ & Trigonometric functions \\
\hline 3. & According to the law of reflection, the definition of the angle of incidence is: \\
\hline$\square \quad$ the angle between the incident ray on a surface and the line \\
$\square \quad$ perpendicular to the surface at the point of incidence \\
\hline $4 . \quad$ According to the law of reflection: \\
\hline$\square \quad$ angle of incidence < angle of reflection \\
$\square \quad$ angle of incidence $=$ angle of reflection \\
$\square \quad$ angle of incidence $>$ angle of reflection
\end{tabular}


Table 2

Comprehension test

\begin{tabular}{ll}
\hline 1. & Which trigonometric function did you use to solve the problem? \\
\hline$\square$ & Sine \\
$\square$ & Cosine \\
\hline 2. & The correct angle of rotation of the mirror is: \\
\hline$\square$ & Half the angle between the incident beam and the reflected beam \\
$\square$ & Equal to the angle between the incident beam and the reflected beam \\
$\square$ & Double the angle between the incident beam and the reflected beam \\
\hline 3. & The correct angle of rotation of the mirror is: \\
\hline$\square$ & Half the angle of incidence \\
$\square$ & Equal to the angle of incidence \\
$\square$ & Double the angle of incidence \\
\hline 4. & The correct angle of rotation of the mirror is: \\
\hline$\square$ & Half the angle of reflection \\
$\square$ & Equal to the angle of reflection \\
$\square$ & Double the angle of reflection
\end{tabular}

Presence was measured using the Temple Presence Inventory (TPI) (Lombard et al., 2000), a crossmedia, multidimensional, well-validated tool (Lombard, Ditton, \& Weinstein, 2009), which was based on 7-point Likert scales. The following dimensions of presence were measured: spatial presence (being there), social presence - actor within medium (being with others), social richness (extent to which the virtual world is perceived as sociable, warm, sensitive, personal or intimate when it used to interact with other people), social realism (extent to which events in the virtual world would or could occur in the real world) and engagement (mental and perceptual immersion).

Satisfaction was measured with one questionnaire item developed by the authors: "Overall, how pleasant do you consider the activity?” on a 7 -point Likert scale $(1=$ not at all, 7 = very much). Additionally, participants could write open-ended comments regarding their experience at the end of the questionnaire.

All sessions were video-recorded for prospective qualitative analysis.

\section{Data collection and statistical tools}

All the tests and questionnaires were administered in electronic format with the SurveyGizmo tool (http://www.surveygizmo.com), except for the drawing test, which was administered by means of paper and pencil. Participants' free comments were coded in order to be quantitatively analysed. All the empirical data was statistically processed with SPSS 19. The variables were tested for normality with Kolmogorov-Smirnov normality tests. Since most of them did not follow the normal distribution, nonparametric statistical tools were used: Mann-Whitney U test to detect differences between groups, Wilcoxon signed rank test to detect differences between pre- and post-tests in the same group and Spearman's rho correlation coefficient to explore relationships between variables in the same group.

\section{Possible confounding variable}

Post-hoc analysis of the cognitive background of participants (Table 3) indicated that Group V participants came mainly from science or technology secondary school backgrounds and had attended more physics and mathematics university courses than Group R participants. It seems that students who attended the SL course and thus were allocated to Group V, were more inclined towards science and technology than those who did not prefer SL courses and thus were allocated to Group R. In order to control for this possible bias in group allocation, the secondary school background was considered a confounding variable and was controlled for using sample stratification. The novelty effect was not considered a confounder for Group V, since its participants were already experienced in it. 
Table 3

Cognitive background of participants

\begin{tabular}{lcccccc}
\hline \multirow{2}{*}{$\begin{array}{c}\text { Secondary school } \\
\text { background }\end{array}$} & \multicolumn{2}{c}{ Mean number of courses on } & \multicolumn{2}{c}{ Group R } & \multicolumn{2}{c}{ Group V } \\
\cline { 2 - 7 } & Mathematics & Physics & $N$ & $\%$ & $N$ & $\%$ \\
\hline Humanities & 2.18 & 1.45 & 60 & 83.3 & 34 & 43.6 \\
Science-Technology & 3.80 & 2.09 & 12 & 16.7 & 44 & 56.4 \\
\hline
\end{tabular}

\section{Procedure}

Real world

Initially, three pilot sessions were conducted in order to solve technical problems regarding video recording. The empirical data was gathered from 72 students over 36 sessions. In each session, a pair of students and the facilitator (the first author) participated (Figure 2). The duration of each session was approximately 37 minutes. Before each session students answered a questionnaire on demographics and the pre-test. Then they followed the facilitator to the room where the activity took place. There, a brief introductory lesson was given by the facilitator, reminding students of the laws of reflection and basic trigonometry, and students familiarised themselves with the use of the laser and the rotating mirror. Then the facilitator informed them about the problem they had to solve collaboratively and that he would remain available for assistance during the session (scaffolding). After the end of the activity, students completed the tests and questionnaires regarding learning outcome, satisfaction and presence.

\section{Virtual world}

The empirical data was gathered from 78 students over 39 sessions. In each session, a pair of students and the facilitator participated. The three participants were physically located in three different rooms and communicated only through SL, using a headset and voice chat. During the session, the screen, microphone, and webcam of each participant were recorded (Figure 3). The duration of each session was approximately 48 minutes. Before the session, students answered the same questionnaire as in the real world. Then they logged in SL using their own accounts and avatars, and were asked to teleport to the sandbox (experimentation space) of the Earthlab Education Island. The procedure followed was the same as with the students in the real world.

\section{Results}

\section{Learning outcome}

Table 4 presents the scores of the tests measuring the learning outcome. Pre-test scores were moderate in both groups, but Group V scored statistically higher than Group R. Nevertheless, all the scores of the tests taken after the activity were high, and no statistical differences were detected between groups. In order to control for the possible confounding variable (secondary school background, i.e., the possibility that the different cognitive background of the two groups might have influenced the results), the sample was stratified into two groups: humanities and science-technology (Table 5). No statistically significant differences were detected between groups on any background, which indicates that secondary school background was not a confounding variable for the overall learning outcome.

Table 4

Learning outcome

\begin{tabular}{lcccccccc}
\hline & \multicolumn{3}{c}{ Group R } & \multicolumn{3}{c}{ Group V } & \multicolumn{2}{c}{ Mann-Whitney UT } \\
\hline & $N$ & Mean & $S D$ & $N$ & Mean & $S D$ & $Z$ & $p$ \\
\hline Pre-test (0-4) & 72 & 2.21 & 1.23 & 78 & 2.82 & 1.12 & -3.066 & $.002^{* *}$ \\
\hline Post-test (0-4) & 72 & 3.68 & .57 & 78 & 3.58 & .74 & -.579 & .563 \\
Comprehension test (0-4) & 72 & 3.38 & .97 & 78 & 3.59 & .692 & -1.047 & .295 \\
Drawing (0-8) & 72 & 7.17 & 1.40 & 78 & 7.45 & 1.08 & -1.371 & .171 \\
\hline $\begin{array}{l}\text { Overall learning outcome } \\
(0-16)\end{array}$ & 72 & 14.22 & 2.20 & 78 & 14.61 & 2.01 & -1.324 & .185 \\
$* * p<0.01$. & & & & & & & &
\end{tabular}


Table 5

Stratification of overall learning outcome according to secondary school background

\begin{tabular}{|c|c|c|c|c|c|c|c|c|}
\hline & \multicolumn{3}{|c|}{ Group R } & \multicolumn{3}{|c|}{ Group V } & \multicolumn{2}{|c|}{ Mann-Whitney UT } \\
\hline $\begin{array}{l}\text { Secondary school } \\
\text { background }\end{array}$ & $N$ & Mean & $S D$ & $N$ & Mean & $S D$ & $Z$ & $p$ \\
\hline Humanities & 60 & 13.96 & 2.29 & 34 & 13.76 & 2.27 & -.553 & .580 \\
\hline Science-Technology & 12 & 15.50 & 1.00 & 44 & 15.27 & 1.51 & -.218 & .827 \\
\hline
\end{tabular}

\section{Satisfaction}

Satisfaction was very high in both environments (Group R: mean $=5.86, S D=1.27$, Group V: Mean $=$ $6.09, S D=.96)$, although the difference was not statistically significant $(Z=-.733, p=.464)$. In order to control for the possible confounding variable (secondary school background), the sample was again stratified (Table 6). No statistically significant differences were detected between groups with any background, which indicates that secondary school background was not a confounding variable for satisfaction.

Table 6

Stratification of satisfaction according to secondary school background

\begin{tabular}{lcccccccc}
\hline & \multicolumn{3}{c}{ Group R } & \multicolumn{3}{c}{ Group V } & \multicolumn{3}{c}{ Mann-Whitney UT } \\
\hline $\begin{array}{l}\text { Secondary school } \\
\text { background }\end{array}$ & $N$ & Mean & $S D$ & $N$ & Mean & $S D$ & $Z$ & $p$ \\
\hline Humanities & 60 & 5.80 & 1.28 & 34 & 6.09 & .99 & -.906 & .365 \\
Science-Technology & 12 & 6.17 & 1.19 & 44 & 6.09 & .96 & -.707 & .479 \\
\hline
\end{tabular}

\section{Presence}

Table 7 presents the scores for presence dimensions in the virtual environment according to the TPI questionnaire. The reliability of all TPI presence dimensions was found to be high $(\alpha>$.7). Social dimensions of presence and engagement scored high, while spatial presence was only moderate.

Table 7

TPI presence dimensions in the virtual environment

\begin{tabular}{lccccc}
\hline & $N$ & Mean & SD & Cronbach's alpha & Items \\
\hline Spatial presence & 78 & 4.50 & 1.08 & .781 & 7 \\
Social presence & 78 & 5.37 & .77 & .735 & 7 \\
Social richness & 78 & 5.40 & 1.02 & .878 & 7 \\
Social realism & 78 & 5.61 & 1.24 & .840 & 3 \\
Engagement & 78 & 5.47 & 1.06 & .914 & 6 \\
\hline
\end{tabular}

\section{Correlations}

Table 8 presents Spearman's rho correlation coefficients regarding learning outcome, satisfaction, and presence dimensions for the virtual world condition. The overall learning outcome was not correlated with any presence dimension. Nevertheless, satisfaction was positively correlated with all presence dimensions, and more strongly with social richness and engagement.

Table 8

Spearman's rho correlation coefficients (virtual world condition)

\begin{tabular}{lccccccc}
\hline & $\begin{array}{l}\text { Overall } \\
\text { learning } \\
\text { outcome }\end{array}$ & Satisfaction & $\begin{array}{l}\text { Spatial } \\
\text { presence }\end{array}$ & $\begin{array}{l}\text { Social } \\
\text { presence }\end{array}$ & $\begin{array}{l}\text { Social } \\
\text { richness }\end{array}$ & $\begin{array}{l}\text { Social } \\
\text { realism }\end{array}$ & Engagement \\
\hline $\begin{array}{l}\text { Overall learning } \\
\text { outcome }\end{array}$ & - & & & & & \\
Satisfaction & .206 & - & & & & \\
Spatial presence & .120 & $.376^{* *}$ & - & & & \\
Social presence & .007 & $.432^{* *}$ & $.536^{* *}$ & - & & \\
Social richness & .038 & $.651^{* *}$ & $.385^{* *}$ & $.426^{* *}$ & - & \\
Social realism & .132 & $.399^{* *}$ & $.303^{* *}$ & $.303^{* *}$ & $.491^{* *}$ & - \\
Engagement & .158 & $.667^{* *}$ & $.580^{* *}$ & $.599^{* *}$ & $.705^{* *}$ & $.456^{* *}$ & - \\
\hline
\end{tabular}




\section{Free comments}

Most participants (66\%) wrote a free comment at the end of the questionnaire. Overall, 50 comments were collected from the 72 participants of Group R (69\%) and 49 comments from the 78 participants of Group V (63\%). These comments were carefully read by the first author in order to find recurring themes. A short label or code was given to the most frequent remarks. Table 9 presents the frequencies of all codes sorted in descending order according to Group $\mathrm{R}$ and then to Group V. Frequencies are given as absolute values $(N)$, as percentages of the sum of all codes (\% codes) and as percentages of the sum of all comments (\% comments). The codes were classified as positive or negative. Negative codes are indicated in gray cells.

Table 9

Free comment coding frequencies

\begin{tabular}{|c|c|c|c|c|c|c|}
\hline \multirow[t]{2}{*}{ Code name** } & \multicolumn{3}{|c|}{ Group R } & \multicolumn{3}{|c|}{ Group V } \\
\hline & $N^{*}$ & $\begin{array}{c}\% \\
\text { codes } \\
(N / 100)\end{array}$ & $\begin{array}{c}\% \\
(N / 50)\end{array}$ & $N$ & $\begin{array}{c}\% \\
\text { codes } \\
(N / 117)\end{array}$ & $\begin{array}{c}\% \\
(N / 49)\end{array}$ \\
\hline $\begin{array}{l}\text { Practical application of theoretical } \\
\text { knowledge }\end{array}$ & 15 & 15.0 & 30.0 & 0 & 0 & 0 \\
\hline Overall satisfaction & 12 & 12.0 & 24.0 & 20 & 17.1 & 40.8 \\
\hline Interesting activity & 12 & 12.0 & 24.0 & 17 & 14.5 & 34.7 \\
\hline Positive presence of facilitator & 11 & 11.0 & 22.0 & 1 & 0.9 & 2.0 \\
\hline $\begin{array}{l}\text { Positive educational environment } \\
\text { design }\end{array}$ & 10 & 10.0 & 20.0 & 6 & 5.1 & 12.2 \\
\hline Learning & 8 & 8.0 & 16.0 & 1 & 0.9 & 2.0 \\
\hline Impressed with target fall & 6 & 6.0 & 12.0 & 1 & 0.9 & 2.0 \\
\hline Satisfactory collaboration & 5 & 5.0 & 10.0 & 7 & 6.0 & 14.3 \\
\hline $\begin{array}{l}\text { Anxiety-awkwardness due to } \\
\text { video recording }\end{array}$ & 5 & 5.0 & 10.0 & 0 & 0 & 0 \\
\hline Wish for more similar activities & 3 & 3.0 & 6.0 & 6 & 5.1 & 12.2 \\
\hline Difficult activity & 3 & 3.0 & 6.0 & 1 & 0.9 & 2.0 \\
\hline Preference to real environment & 2 & 2.0 & 4.0 & 3 & 2.6 & 6.1 \\
\hline General anxiety about the activity & 2 & 2.0 & 4.0 & 1 & 0.9 & 2.0 \\
\hline Directness & 2 & 2.0 & 4.0 & 0 & 0 & 0 \\
\hline Unprecedented activity & 1 & 1.0 & 2.0 & 5 & 4.3 & 10.2 \\
\hline Small room & 1 & 1.0 & 2.0 & 4 & 3.4 & 8.2 \\
\hline Engagement & 1 & 1.0 & 2.0 & 1 & 0.9 & 2.0 \\
\hline Not satisfactory environment & 1 & 1.0 & 2.0 & 0 & 0 & 0 \\
\hline $\begin{array}{l}\text { Need for more non-verbal } \\
\text { communication }\end{array}$ & 0 & 0 & 0 & 8 & 6.8 & 16.3 \\
\hline Difficulty in using camera & 0 & 0 & 0 & 5 & 4.3 & 10.2 \\
\hline Difficulty in using rulers & 0 & 0 & 0 & 4 & 3.4 & 8.2 \\
\hline Realistic environment & 0 & 0 & 0 & 3 & 2.6 & 6.1 \\
\hline Whiteboard usefulness & 0 & 0 & 0 & 3 & 2.6 & 6.1 \\
\hline Preference to virtual environment & 0 & 0 & 0 & 3 & 2.6 & 6.1 \\
\hline $\begin{array}{l}\text { SL potential for laboratory } \\
\text { activities }\end{array}$ & 0 & 0 & 0 & 3 & 2.6 & 6.1 \\
\hline Not satisfactory voice chat & 0 & 0 & 0 & 3 & 2.6 & 6.1 \\
\hline Voice chat usefulness & 0 & 0 & 0 & 2 & 1.7 & 4.1 \\
\hline Social presence & 0 & 0 & 0 & 2 & 1.7 & 4.1 \\
\hline Spatial presence & 0 & 0 & 0 & 2 & 1.7 & 4.1 \\
\hline Difficulty in using whiteboard & 0 & 0 & 0 & 2 & 1.7 & 4.1 \\
\hline Interactive environment & 0 & 0 & 0 & 1 & 0.9 & 2.0 \\
\hline Object usability & 0 & 0 & 0 & 1 & 0.9 & 2.0 \\
\hline Discontentment - Headache & 0 & 0 & 0 & 1 & 0.9 & 2.0 \\
\hline Total & 100 & 100.0 & 200.0 & 117 & 100.0 & 238.8 \\
\hline
\end{tabular}

*Table sorted according to Group $\mathrm{R}$ and then Group V code frequency (descending order)

**White cells refer to positive codes; gray cells refer to negative codes. 


\section{Discussion}

\section{Learning outcome}

Group V participants scored statistically higher (2.82) on the pre-test than Group R (2.21), which was expected because most of them came from science or technology secondary school backgrounds and had attended more physics and mathematics university courses than Group R participants. The post-test scores were statistically higher than the pre-tests in both groups according to related samples Wilcoxon signed rank test (Group $\mathrm{R}: \mathrm{Z}=-6.437, p<0.01$, Group V: $Z=-5.696, p<0.01$ ). This shows that students constructed knowledge during the activity in both environments. Moreover, the fact that no statistically significant differences were detected between groups on any test taken after the activity (post-test, comprehension test, drawing test, and overall learning outcome) indicates that the acquired knowledge was the same in both environments.

In order to control for the possible confounding variable (secondary school background, i.e., the possibility that the different cognitive background of the two groups might have influenced results), the sample was stratified but no statistically significant differences were detected between groups. This leads to the conclusion that the virtual implementation of the laboratory PBL activity was equally effective to its real world equivalent in terms of learning outcome, which means that hypothesis H1 (student learning outcomes will not differ between conditions) can be accepted. This result is supported by many other comparative studies between virtual and real worlds (Beltrán Sierra et al., 2012; Cobb et al., 2009; Dalgarno et al., 2009; Hickey et al., 2009; Ketelhut et al., 2010; Sutcliffe \& Alrayes, 2012), but this is the first study to verify it for a hands-on laboratory PBL activity in higher education.

The overall learning outcome was not correlated with any presence dimension in Group V, which means that hypothesis H2 (student learning outcomes will be positively correlated to presence in the virtual world condition) should be rejected. This result could be attributed to the collaborative nature of the PBL activity, which is mostly based on effective communication and concomitantly on social presence. In this study social dimensions of presence were high and did not have large variability, thus preventing strong correlations with the learning outcome to be established. Studies that have found positive correlations with presence are usually related to learning content that depends on effective spatial representation, like electromagnetism (Salzman et al., 1999) or frog anatomy (Lee et al., 2010).

\section{Satisfaction}

The results show that participants were very satisfied in both environments. In order to control for the possible confounding variable (secondary school background), the sample was stratified but again no statistically significant differences were detected between groups. This leads to the conclusion that the virtual implementation of the laboratory PBL activity was equally satisfactory to its real world equivalent, which means that hypothesis H3 (student satisfaction will not differ between conditions) should be accepted. This result is somewhere in the middle regarding the related literature. Beltrán Sierra et al. (2012) found that SL increases motivation and promotes participation and investigation, due to the fact that it makes learning possible in a more pleasant, interactive and deeper way than if it had been taught in the classroom. In contrast, Sutcliffe and Alrayes (2012) found that the face-to-face condition offered a better experience, more ease of use, and overall satisfaction than SL, although their informal observations suggested that SL increased motivation and engagement because of the stimulating and different experience.

Satisfaction was positively correlated with all presence dimensions, and more strongly with social richness and engagement, which means that hypothesis H4 (student satisfaction will be positively correlated with presence in the virtual world condition) should be accepted. This is in accordance with the literature supporting that social presence is positively correlated with student satisfaction in CSCL activities (Bulu, 2012; Copley Cobb, 2009; Gunawardena \& Zittle, 1997; Hostetter \& Busch, 2006; Richardson \& Swan, 2003).

\section{Presence}

Although spatial presence was found to be moderate, social dimensions and engagement scored high, similarly to Vrellis et al. (2012). The medium scores of spatial presence are related to the desktop virtual 
reality nature of SL, while the higher scores of engagement and social dimensions of presence are related to the social nature of MUVEs and the collaborative nature of the PBL activity. The high level of social presence induced in MUVEs could eliminate the perceived isolation that students face when using single user platforms, because it recreates the social context of interaction and collaboration among students and teachers that exists in traditional hands-on laboratories (Feisel \& Rosa, 2005; Vargas et al., 2011).

\section{Free comments}

Overall, 66\% of the participants wrote a free comment (Group R $=69 \%$, Group V = 63\%). Ninety-two percent of the comments from participants of Group R and 91.8\% of the comments from participants of Group V contained at least one positive code. This indicates that almost every participant who wrote a comment, made a positive remark in both groups. Nevertheless, $51 \%$ of the comments of Group V contained at least one negative code, in contrast to only $20 \%$ of the Group R. This suggests that there were more than twice the number of comments with at least one negative remark in the Group V. This higher frequency of negative remarks in Group $\mathrm{V}$ does not imply that the virtual environment was less pleasurable, but rather the fact that the virtual world of SL is a mediated environment that poses several limitations in non-verbal communication, motion and sound, in addition to control demands for the avatar and the camera. In addition, the fact that the highest frequency code in Group $\mathrm{V}$ was overall satisfaction (17.1\%), which was only second in frequency in Group R (12\%), might even suggest that the participants in Group $\mathrm{V}$ were more satisfied with their experience, although this was not confirmed by the corresponding questionnaire item (Table 6). In sum, the findings from the free comments seem to imply that Group V participants were at least as satisfied as Group R participants, despite the mediation-related difficulties and limitations.

The most frequent positive code in Group R (15\%) was practical application of theoretical knowledge, yet, this code did not appear at all in any comment from Group V. This might imply that students in Group V did not consider their experience as practical application of theoretical knowledge to the extent of those in Group R. In addition, although the code learning appeared with 8\% frequency in Group R, it only appeared in $0.9 \%$ of codes in Group V. This is in accordance with the much lower frequency $(0.9 \%)$ of the positive presence of facilitator code in Group V compared to $11 \%$ in Group R. The above might indicate that the virtual environment was experienced by the participants as less educational than the real one. At first, this seems to moderate its learning affordances. Nevertheless, if the fact that the measured overall learning outcome was the same in both environments is taken into account, it might imply that the participants of the virtual environment perceived it more as an informal or implicit learning environment (Eraut, 2000; Reber, 1996). This is in correspondence with the fact that the facilitator was more invisible in the virtual environment.

The code "interesting activity" had similar and a relatively high frequency in both environments $(\mathrm{R}=12 \%$, $\mathrm{V}=14.5 \%)$ along with the code "satisfactory collaboration" ( $\mathrm{R}=5 \%, \mathrm{~V}=6 \%)$, indicating that laboratory PBL activities can engage participants in satisfactory collaboration regardless of the implementation environment.

The most frequent negative code in Group R (5\%) was “anxiety - awkwardness due to video recording”. Nevertheless, this code did not appear at all in the comments of Group V, although screen and video capture were taking place there too. This might imply that video recording is more stressful in the real environment. Additionally, the more general code "anxiety" was more frequent in the real environment (Group $\mathrm{R}=2 \%$, Group V = .9\%), implying that participation in a PBL activity might be more stressful in the real than in the virtual world. This can be attributed to the fact that the real environment requires physical attendance and action from the participants, in contrast to the virtual environment, which only requires mediated presence and allows for more isolated participation. Experimentation in a virtual world has the advantage that it can occur without the constraints of real world consequences and stresses, which aids in creating that state of relaxed alertness while sitting in front of a computer and navigating through the virtual world (Bell, Smith-Robbins, \& Withnail, 2010). Another reason for the higher frequency of "anxiety" code in Group R may be the lack of prior learning in science and mathematics, which was also suggested by the higher frequency of the code "difficult activity" (Group R = 3\%, Group V = .9\%).

Interestingly, the frequency of the negative code "small room" was more prevalent in the virtual environment (3.4\%), than the real (1\%). This indicates experience of spatial presence by the participants of Group V. Moreover, it could indicate the possible need for representing virtual spaces in larger 
dimensions than the real ones, because (a) users seem to underestimate the dimensions of virtual spaces (Henry \& Furness, 1993) and (b) users have less precise control over their avatars, in relation to the more precise control of their bodies in the real world.

The more frequent negative code in Group V (6.8\%) was the "need for more non-verbal communication", which implies its importance for the participants. The importance of non-verbal communication in virtual environments has been recognised in literature (Verhulsdonck \& Morie, 2009; Wigham \& Chanier, 2013), and new promising virtual worlds like High Fidelity are starting to capture and stream facial expressions and body language using inexpensive webcams and motion controllers (http://www.highfidelity.com). The next more frequent negative codes in Group V were related to control and technical difficulties (camera, rulers, voice chat quality, and whiteboard). Control problems could be reduced in the future with the use of natural user interfaces (Francese, Passero, \& Tortora, 2012), while technical problems like voice quality will be eliminated with the continuous bandwidth increase of Internet connections.

\section{Limitations}

One possible confounder that could weaken the internal validity of the study was the dissimilar cognitive background of the groups. However, it was demonstrated through sample stratification that it did not affect the results. Another fact that could be viewed as a limitation was the difference in the mean session duration between groups. Group V sessions lasted on average 11 minutes longer (30\%) than Group R sessions. Nevertheless, literature suggests that it is not unusual for tasks to take longer to complete via computer-mediated communication in comparison to face-to-face communication. This generally does not affect task performance and is usually due to typing in text-based environments (Bordia, 1997) or due to usability issues in virtual environments (Sutcliffe \& Alrayes, 2012).

The main limitation of the study was the gender imbalanced sample which limits the external validity of the study to university students from the Department of Primary Education, mostly women. In order to extend the external validity of the conclusions, more empirical studies are needed that will focus on different student cohorts and disciplines, for example, chemistry, medicine, or engineering. More specifically, a possible future extension of this research would involve the implementation and evaluation of a new laboratory PBL activity in collaboration with the Chemistry Department. The empirical evaluation with chemistry students would provide insights regarding the effectiveness and acceptance of such activities at more hard-science departments. It would also have the benefit of a more balanced student gender ratio.

\section{Conclusion}

The aim of this study was to compare in terms of learning outcomes, satisfaction, and presence a simple laboratory PBL activity about the reflection of light implemented in the real world and the virtual world. The virtual environment (SL) elicited the same overall learning outcome and satisfaction as the real one. The participants of the virtual environment experienced high levels of engagement and social presence dimensions, but moderate levels of spatial presence. All presence dimensions were positively correlated with satisfaction, but not with the learning outcomes. There were also indications that SL was perceived as more pleasurable and informal learning environment, while reality was more stressful.

Overall, it was found that MUVEs like SL can be used effectively as platforms for laboratory PBL activities. Their use as complementary or alternative environments (Dalgarno et al., 2009; Feisel \& Rosa, 2005; Torres et al., 2006) could enable the connection of PBL to the real world, and at the same time provide safe, low-cost and highly available constructive and situated learning environments for local or distance learners. 


\section{References}

Allen, D., \& Hodson, R. C. (2003, June). Crops of the future: A problem-based learning exercise for the laboratory. Paper presented at the 25th Workshop/Conference of the Association for Biology Laboratory Education (ABLE), Las Vegas, Nevada.

Allen, D., \& Tanner, K. (2003). Approaches to cell biology teaching: Learning content in context Problem-based learning. Cell Biology Education, 2(2), 73-81. doi:10.1187/cbe.03-04-0019

Barab, S. A., Sadler, T. D., Heiselt, C., Hickey, D., \& Zuiker, S. (2006). Relating narrative, inquiry, and inscriptions: Supporting consequential play. Journal of Science Education and Technology, 16(1), 5982. doi:10.1007/s10956-006-9033-3

Barrows, H. S. (1986). A taxonomy of problem-based learning methods. Medical Education, 20(6), 481486. doi:10.1111/j.1365-2923.1986.tb01386.x

Bell, M. W., Smith-Robbins, S., \& Withnail, G. (2010). This is not a game - Social virtualworlds, fun, and learning. In A. Peachey (Ed.), Researching learning in virtual worlds (pp. 177-191). London: Springer-Verlag.

Beltrán Sierra, L. M., Gutiérrez, R. S., \& Garzón-Castro, C. L. (2012). Second Life as a support element for learning electronic related subjects: A real case. Computers \& Education, 58(1), 291-302. doi:10.1016/j.compedu.2011.07.019

Biocca, F., Harms, C., \& Burgoon, J. K. (2003). Toward a more robust theory and measure of social presence: Review and suggested criteria. Presence: Teleoperators and Virtual Environments, 12(5), 456-480. doi:10.1162/105474603322761270

Bordia, P. (1997). Face-to-face versus computer-mediated communication: A yynthesis of the experimental literature. Journal of Business Communication, 34(1), 99-118. doi:10.1177/002194369703400106

Bowe, B., Flynn, C., Howard, R., \& Daly, S. (2003). Teaching physics to engineering students using problem-based learning. International Journal of Engineering Education, 19(5), 742-746. Retrieved from http://www.ijee.ie/articles/Vol19-5/IJEE1446.pdf

Bulu, S. T. (2012). Place presence, social presence, co-presence, and satisfaction in virtual worlds. Computers \& Education, 58(1), 154-161. doi:10.1016/j.compedu.2011.08.024

Callaghan, M., McCusker, K., Losada, J. L., Harkin, J., \& Wilson, S. (2009). Engineering Education Island: Teaching engineering in virtual worlds. ITALICS, Innovation in Teaching And Learning in Information and Computer Sciences, 8(3), 2-18. Retrieved from

https://www.heacademy.ac.uk/sites/default/files/ital.8.3b.pdf

Chen, C. J. (2006). The design, development and evaluation of a virtual reality based learning environment. Australasian Journal of Educational Technology, 22(1), 39-63. Retrieved from http://ajet.org.au/index.php/AJET/article/view/1306

Cobb, S., Heaney, R., \& Henderson-Begg, S. (2009). The learning gains and student perceptions of a Second Life Virtual Lab. Bioscience Education, 13(5). Retrieved from http://www.bioscience.heacademy.ac.uk/journal/vol13/beej-13-5.aspx

Copley Cobb, S. (2009). Social presence and online learning: a current view from a research perspective. Journal of Interactive Online Learning, 8(3), 241-254. Retrieved from http://www.ncolr.org/issues/jiol/v8/n3/social-presence-and-online-learning-a-current-view-from-aresearch-perspective\#.Vh6qMWQrK-o

Dalgarno, B., Bishop, A. G., Adlong, W., \& Bedgood, D. R. (2009). Effectiveness of a virtual laboratory as a preparatory resource for distance education chemistry students. Computers \& Education, 53(3), 853-865. doi:10.1016/j.compedu.2009.05.005

Dalgarno, B., \& Lee, M. J. W. (2010). What are the learning affordances of 3-D virtual environments? British Journal of Educational Technology, 41(1), 10-32. doi:10.1111/j.1467-8535.2009.01038.x

de Freitas, S., \& Veletsianos, G. (2010). Editorial: Crossing boundaries: Learning and teaching in virtual worlds. British Journal of Educational Technology, 41(1) , 3-9, doi:10.1111/j.14678535.2009.01045.x

Dede, C., Nelson, B., Ketelhut, D. J., Clarke, J., \& Bowman, C. (2004). Design-based research strategies for studying situated learning in a multi-user virtual environment. In Y. B. Kafai, W. A. Sandoval, N. Enyedy, A. S. Nixon, \& F. Herrera (Eds.), Proceedings of the 6th International Conference on Learning Sciences (pp. 158-165) Mahwah, NJ: Earlbaum. Retrieved from https://www.isls.org/icls/2004/

Dickey, M. D. (2005). Brave new (interactive) worlds: A review of the design affordances and constraints of two 3D virtual worlds as interactive learning environments. Interactive Learning Environments, 13(1-2), 121-137. doi:10.1080/10494820500173714 
Domin, D. S. (1999). A review of laboratory instruction styles. Journal of Chemical Education, 76(4), 543. doi:10.1021/ed076p543

Eraut, M. (2000). Non-formal learning and tacit knowledge in professional work. British Journal of Educational Psychology, 70(1), 113-136. doi:10.1348/000709900158001

Fayolle, J., Gravier, C., \& Jailly, B. (2010, August). Collaborative remote laboratory in virtual world. Paper presented at the 10th WSEAS International Conference on Applied Informatics And Communications, Taipei, Taiwan.

Feisel, L. D., \& Rosa, A. J. (2005). The role of the laboratory in undergraduate engineering education. Journal of Engineering Education, 94(1), 121--130. doi:10.1002/j.2168-9830.2005.tb00833.x

Francese, R., Passero, I., \& Tortora, G. (2012, May). Wiimote and Kinect: gestural user interfaces add a natural third dimension to HCI. In G. Tortora, S. Levialdi, \& M. Tucci (Eds.), Proceedings of the International Working Conference on Advanced Visual Interfaces (pp. 116-123). New York, NY: ACM Press. doi:10.1145/2254556.2254580

Gallagher, S. A., Sher, B. T., Stepien, W. J., \& Workman, D. (1995). Implementing problem-based learning in science classrooms. School Science and Mathematics, 95(3), 136-146. doi:10.1111/j.19498594.1995.tb15748.x

Gunawardena, C. N., \& Zittle, F. J. (1997). Social presence as a predictor of satisfaction within a computer-mediated conferencing environment. American Journal of Distance Education, 11(3), 8-26. doi:10.1080/08923649709526970

Heeter, C. (1992). Being there: The subjective experience of presence. Presence: Teleoperators and Virtual Environments, 1(2), 262-271. Retrieved from http://commtechlab.msu.edu/randd/research/beingthere.html

Henry, D., \& Furness, T. (1993, September). Spatial perception in virtual environments: Evaluating an architectural application. Paper presented at the IEEE Virtual Reality Annual International Symposium, Seattle, Washington. doi:10.1109/VRAIS.1993.380801

Hew, K. F., \& Cheung, W. S. (2010). Use of three-dimensional (3-D) immersive virtual worlds in K-12 and higher education settings: A review of the research. British Journal of Educational Technology, 41(1), 33-55. doi:10.1111/j.1467-8535.2008.00900.x

Hickey, D., Ingram-Goble, A., \& Jameson, E. (2009). Designing assessments and assessing designs in virtual educational environments. Journal of Science Education and Technology, 18(2), 187-208. doi:10.1007/s10956-008-9143-1

Hmelo-Silver, C. E. (2004). Problem-based learning: What and how do students learn? Educational Psychology Review, 16(3), 235-266. doi:10.1023/B:EDPR.0000034022.16470.f3

Hmelo-Silver, C. E., \& Eberbach, C. (2012). Learning theories and problem-based learning. In S. Bridges, C. McGrath, \& T. L. Whitehill (Eds.), Problem-based learning in clinical education (Vol. 8, pp. 3-17). Dordrecht: Springer.

Hostetter, C., \& Busch, M. (2006). Measuring up online: The relationship between social presence and student learning satisfaction. Journal of Scholarship of Teaching and Learning, 6(2), 1-12. Retrieved from http://josotl.indiana.edu/article/view/1670

Hung, W., Jonassen, D. H., \& Liu, R. (2008). Problem-based learning. In J. M. Spector (Ed.), Handbook of research on educational communications and technology (3rd ed., pp. 485-506). New York, NY: Taylor \& Francis.

Jonassen, D. H. (1994). Thinking technology: Toward a constructivist design model. Educational Technology, 34(4), 34-37. Retrieved from ERIC database. (EJ481852)

Jonassen, D. H. (2000). Toward a design theory of problem solving. Educational Technology Research and Development, 48(4), 63-85. doi:10.1007/bf02300500

Kelly, O. C., \& Finlayson, O. E. (2007). Providing solutions through problem-based learning for the undergraduate 1st year chemistry laboratory. Chemistry Education Research and Practice, 8(3), 347361. doi:10.1039/b7rp90009k

Ketelhut, D. J., Nelson, B. C., Clarke, J., \& Dede, C. (2010). A multi-user virtual environment for building and assessing higher order inquiry skills in science. British Journal of Educational Technology, 41(1), 56-68. doi:10.1111/j.1467-8535.2009.01036.x

Kohnle, A., Brown, T., Rae, C. F., \& Sinclair, B. D. (2012). Problem-based labs and group projects in an introductory university physics course. Physics Education, 47(4), 476.

Kreijns, K., Kirschner, P. A., Jochems, W., \& van Buuren, H. (2007). Measuring perceived sociability of computer-supported collaborative learning environments. Computers \& Education, 49(2), 176-192. doi:10.1016/j.compedu.2005.05.004 
Lee, E. A.-L., Wong, K. W., \& Fung, C. C. (2010). How does desktop virtual reality enhance learning outcomes? A structural equation modeling approach. Computers \& Education, 55(4), 1424-1442. doi:10.1016/j.compedu.2010.06.006

Lombard, M., \& Ditton, T.. Crane, D., Davis, B., Gil-Egui, Horvath, K., \& Rossman, J. (2000, March). Measuring presence: A literature-based approach to the development of a standardized paper-andpencil instrument. Paper presented at the Presence 2000: The Third International Workshop on Presence, Delft, The Netherlands. Retrieved from http://astro.temple.edu/ lombard/ISPR/Proceedings/2000/Lombard,\%20Ditton\%20et\%20al.pdf

Lombard, M., Ditton, T. B., \& Weinstein, L. (2009, November). Measuring presence: The Temple Presence Inventory. Paper presented at the Twelfth International Workshop on Presence, Los Angeles, California. Retrieved from http://astro.temple.edu/ lombard/ISPR/Proceedings/2009/Lombard_et_al.pdf

McDonnell, C., O'Connor, C., \& Seery, M. K. (2007). Developing practical chemistry skills by means of student-driven problem based learning mini-projects. Chemistry Education Research and Practice, 8(2), 130-139. doi:10.1039/b6rp90026g

Papachristos, N. M., Vrellis, I., Natsis, A., \& Mikropoulos, T. A. (2014). The role of environment design in an educational multi-user virtual environment. British Journal of Educational Technology, 45(4), 636-646. doi:10.1111/bjet.12056

Reber, A. S. (1996). Implicit learning and tacit knowledge: An essay on the cognitive unconscious. Don Mills: Oxford University Press.

Richardson, J. C., \& Swan, K. (2003). Examining social presence in online courses in relation to students' perceived learning and satisfaction. Journal of Asynchronous Learning Networks, 7(1), 68-88.

Salmon, G. (2009). The future for (second) life and learning. British Journal of Educational Technology, 40(3), 526-538. doi:10.1111/j.1467-8535.2009.00967.x

Salmon, G., \& Hawkridge, D. (2009). Editorial: Out of this world. British Journal of Educational Technology, 40(3), 401-413. doi:10.1111/j.1467-8535.2009.00957.x

Salzman, M. C., Dede, C., Loftin, R. B., \& Chen, J. (1999). A model for understanding how virtual reality aids complex conceptual learning. Presence: Teleoperators and Virtual Environments, 8(3), 293-316. doi:10.1162/105474699566242

Slater, M., McCarthy, J., \& Maringelli, F. (1998). The influence of body movement on subjective presence in virtual environments. Human Factors: The Journal of the Human Factors and Ergonomics Society, 40(3), 469-477. doi:10.1518/001872098779591368

Slater, M., Sadagic, A., Usoh, M., \& Schroeder, R. (2000). Small-group behavior in a virtual and real environment: A comparative study. Presence, 9(1), 37-51. doi:10.1162/105474600566600

Slater, M., Usoh, M., \& Steed, A. (1994). Depth of presence in virtual environments. Presence: Teleoperators and Virtual Environments, 3, 130-144.

Sutcliffe, A., \& Alrayes, A. (2012). Investigating user experience in Second Life for collaborative learning. International Journal of Human-Computer Studies, 70(7), 508-525. doi:10.1016/j.ijhcs.2012.01.005

Svajger, J., \& Valencic, V. (2003). Discovering electricity by computer-based experiments. IEEE Transactions on Education, 46(4), 502-507. doi:10.1109/te.2003.817615

Torres, F., Candelas, F., Puente, S., Pomares, J., Gil, P., \& Ortiz, F. (2006). Experiences with virtual environment and remote laboratory for teaching and learning robotics at the University of Alicante. International Journal of Engineering Education, 22(4), 766-776. Retrieved from http://www.ijee.ie/articles/Vol22-4/08_ijee1799.pdf

Vargas, H., Jose Sanchez, M., Jara, C. A., Candelas, F. A., Torres, F., \& Dormido, S. (2011). A network of automatic control web-based laboratories. IEEE Transactions on Learning Technologies, 4, 197208. doi:10.1109/TLT.2010.35

Verhulsdonck, G., \& Morie, J. F. (2009). Virtual chironomia: Developing non-verbal communication standards in virtual worlds. Journal of Virtual Worlds Research, 2(3) , 3-10. doi:10.4101/jvwr.v2i3.657

Vrellis, I., Papachristos, N. M., Bellou, J., Avouris, N., \& Mikropoulos, T. A. (2010, July). Designing a collaborative learning activity in Second Life: An exploratory study in physics. Paper presented at the 10th IEEE International Conference on Advanced Learning Technologies (ICALT), Sousse, Tunisia.

Vrellis, I., Papachristos, N. M., Natsis, A., \& Mikropoulos, T. A. (2012). Presence in a collaborative science learning activity in Second Life. In A. Jimoyiannis (Ed.), Research on e-learning and ICT in education (pp. 241-251). New York, NY: Springer. 
Wang, F., \& Burton, J. K. (2012). Second Life in education: A review of publications from its launch to 2011. British Journal of Educational Technology, 44(3), 357-371. doi:10.1111/j.14678535.2012.01334.x

Wigham, C. R., \& Chanier, T. (2013). A study of verbal and nonverbal communication in Second Life: The ARCHI21 experience. ReCALL, 25, 63-84. doi:10.1017/S0958344012000250

Corresponding author: Ioannis Vrellis, ivrellis@uoi.gr

Australasian Journal of Educational Technology (C) 2016.

Please cite as: Vrellis, I., Avouris, N., \& Mikropoulos, T.A. (2016). Learning outcome, presence and satisfaction from a science activity in Second Life. Australasian Journal of Educational Technology, 32(1), 59-77. 